\title{
FRONTO-ETHMOIDAL MUCOCELE WITH FRONTAL SINUS DESTRUCTION
}

\author{
Authors \\ M. Gupta (1), Bibhu Pradhan (2) \\ Junior resident -3rd Year (1), Professor \& Head (2), \\ Ganesh Man Singh Memorial Academy of ENT and Head and Neck Studies, \\ TU Teaching Hospital, Kathmandu, Nepal
}

\begin{abstract}
:
Fronto ethmoidal mucocele is a benign but expansive pseudo cyst due to mucous secreting nature of fronto-ethmoid sinus. A rare presentation of frontoethmoidal mucocele was reported. Our subject a 61 years old female presented with frontoethmoidal mucocele of unusually large size and two in number which developed over 2 years. Two masses one above left supra-orbital region and next on forehead was noted along with diplopia and non-axial proptosis in left eye due to swelling. Similar findings were found on CT scan and diagnosis was confirmed during surgery. Endoscopic marsupialisation of fronto-ethmoid pyocele with incision \& drainage of isolated pyocele in the frontal bone was performed under general anaesthesia. A puncture wound in the posterior table of frontal sinus which might have resulted in CSF rhinorrhoea was dealt at the same setting.
\end{abstract}

Keywords: Fronto-ethmoidal mucocele, diplopia, two mucocele, CSF rhinorrhoea

\section{Introduction}

Paranasal mucocele is pseudocyst lined with pseudostratified or low-columnar epithelium containing occasional goblet cells due to obliteration of sinus ostia.Infection in mucocelehaving pus are called pyocele.Although a benign lesion,there isprogressive expansion of mass due to continuous mucous secretion and desquamation causessurrounding tissue displacement and erosion of bony wall of nasal cavity and paranasal sinus. This expansion is in contrast to blocked sinus cavity. Sinus ostia obliteration is due to congenital anomalies, infection, inflammation, trauma, tumor etc.Due to labryinth nature of anatomy of fronthoethmoidal region it is more suseptible to formation of mucocele.

Mucocele occurs with equal frequency among Males and females. Altough mucocele can develop at any age most common presenting age is $40-60$ years. May take $10-15$ years to produce symptoms.Mucocele is extremely rare in children and an association with cystic fibrosis is noted.

Fronthoethmoidal mucocele may present as headache, facial pain, facial deformity, dental pain, nasal obstruction, ophthalmic manifestation (exopthalmous, Periorbital pain, ocular immobility, loss of vision, diplopia). An invasive mucocele may lead to brain abscess, meningitis, meningoencephalitis, seizure, csf fistual etc.

\section{Case presentation}

A 61 years old female patient presented to ENT OPD with chief complain of painless swelling in left fronto-ethmoid region for 2 years and 
painless swelling over the forehead for 1 year. The patient gave history of painless mass of size of pea which was gradually progressive. The patient also complained of blurring of vision and diplopia. She is known diabetic (type II) but have eluded drug for a year.

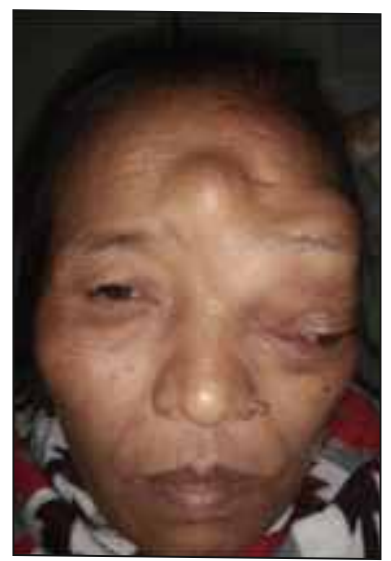

On examination, two swellings were noted. Larger swelling over left supra-orbital region was $4 * 3 \mathrm{~cm}$, cystic, ovoid. It's superior border was $2 \mathrm{~cm}$ above left superior orbital margin. Medially it was at left medial canthus and laterally at left lateral canthus. Smaller swelling over forehead was $2^{*} 2$ $\mathrm{cm}$.lt's superior border was $5 \mathrm{~cm}$ above the right medial canthus, inferior border was $3 \mathrm{~cm}$ above the right medial canthus, medial border lied $3 \mathrm{~cm}$ above the radix of nose whereas lateral border was located at $2 \mathrm{~cm}$ above the middle of right supraorbital margin.

Both the swellings were soft, normal in colour, smooth with well defined margin and were nonmovable but free from overlying skin, with no venous engorgement and pulsation.

During examination of eyes and orbit it was noted that non-axial proptosis was present in left eye due to swelling,diplopiaand blurring of vision . On palpation, obliteration ofleft inferior orbital rim was noted. There was normal mobility of eyeball in all directions.

While examing nose, telecanthus was present but no other external deformity. Nasal cavity was bilaterally patent. Anterior and posterior rhinoscopy was normal. Maxillary sinuses, right ethmoid sinus showed no positive finding. Examination of all the peripheral branches of facial nerve was normal.

Following differential diagnosis were made:

1. Left fronto-ethmoidal mucocele/Pyocoele

2. Pott's Puffy tumour

3. Left fronto-ethmoid Fibrous dysplasia

4. Malignancy (Left Maxilla/ethmoidal/frontal)

Computed topography scan showed an expansile well-defined high-densitylesion in left frontal sinus causing expansion and widening with extension into left orbital cavity causing left eye proptosis with features suggestive of frontal sinus mucocele. Correlating all the clinical and radiological features an initial diagnosis of frontoethmoidal mucocele was made.
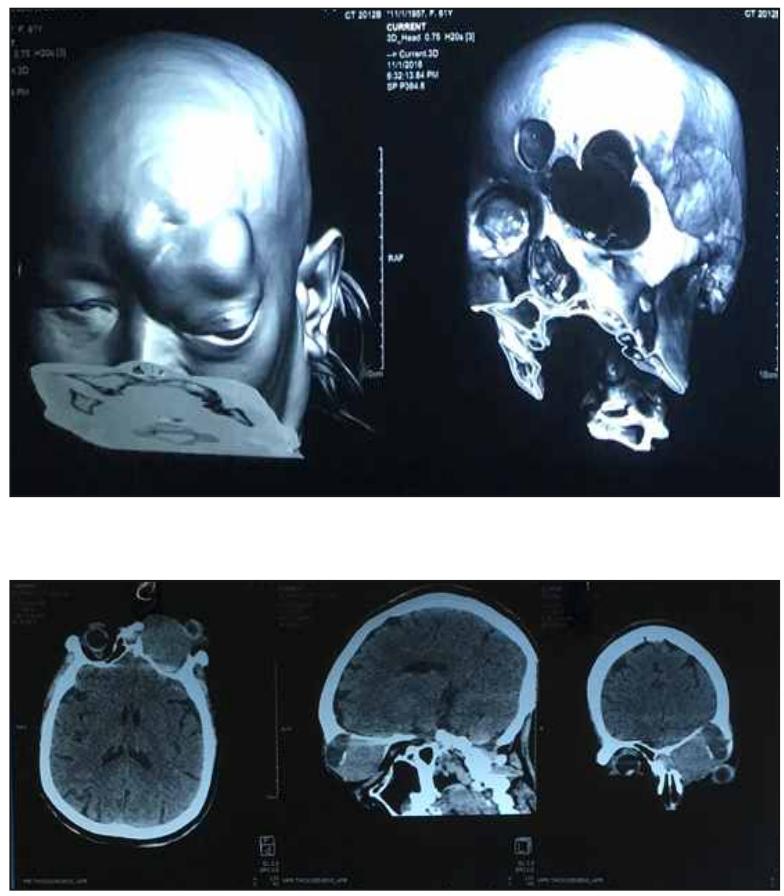

The diagnosis of fronto-ethmoidal mucocele was confirmed during surgery. Endoscopic marsupialization of fronto-ethmoid pyocele was done with isolated pyocele in the frontal bone was performed under general anaesthesia. During the operation, left frontoethmoidal pyocele with formation of single cavity of left frontal, anterior and posterior ethmoid was 


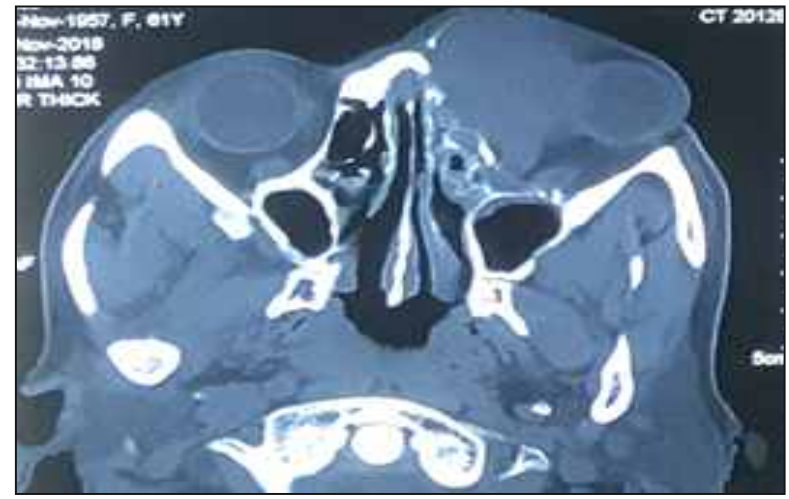

found. Likewise, about $1 * 1 \mathrm{~mm}$ pinpoint erosion of posterior table of frontal sinus with pulsatile CSF leak present. Fat harvested from ear lobule and abdomen and frontal sinus posterior table puncture was closed by bath-plug technique. There also was dehiscence of left lamina papyracea and presence of isolated pyocele cavity in frontal bone in midline. Around $15 \mathrm{ml}$ of pus was aspirated from from the lesion.
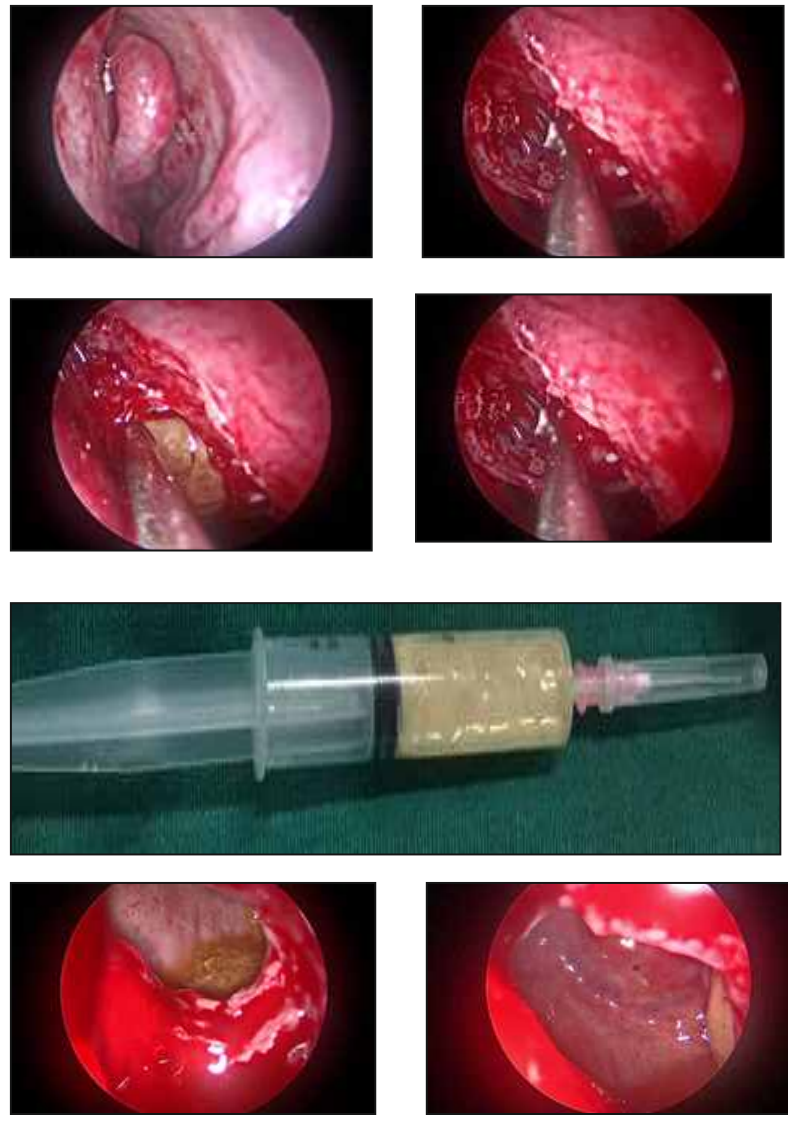

Post-operatively progess was uneventful. Rapid improvement of swelling and proptosis was noted with vision improved
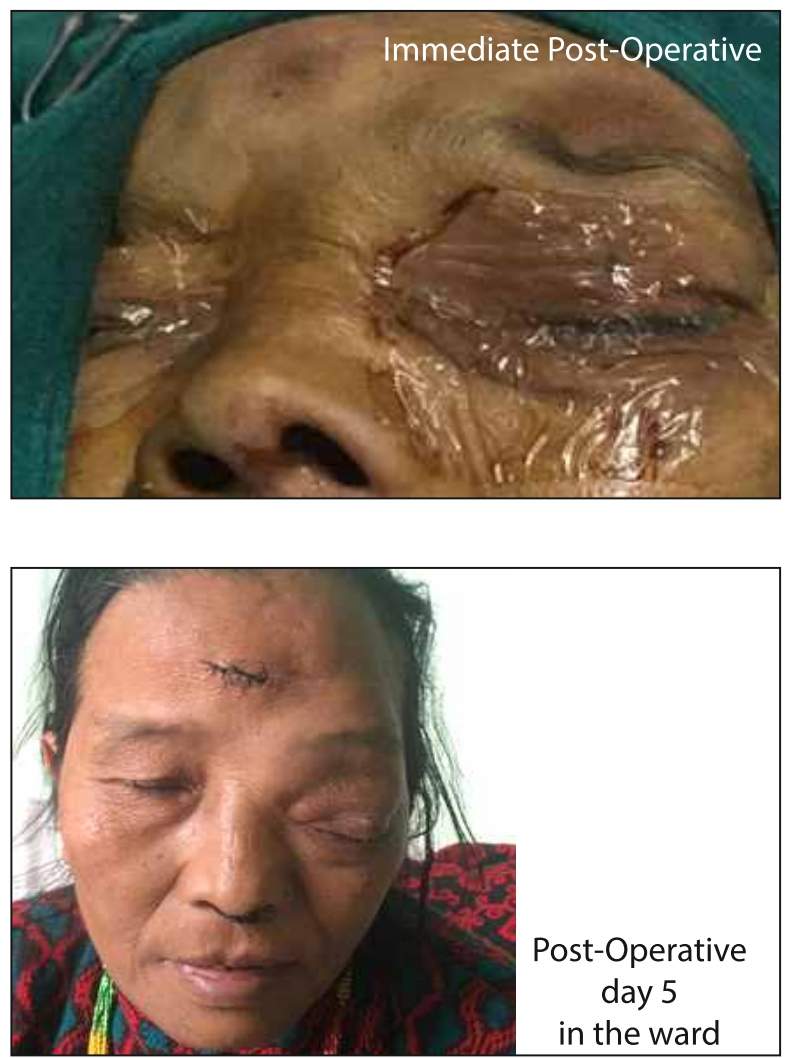

Follow up:no issues or complication were present in the follow up. Her swelling decreased and due to restitution, her proptosis improved.

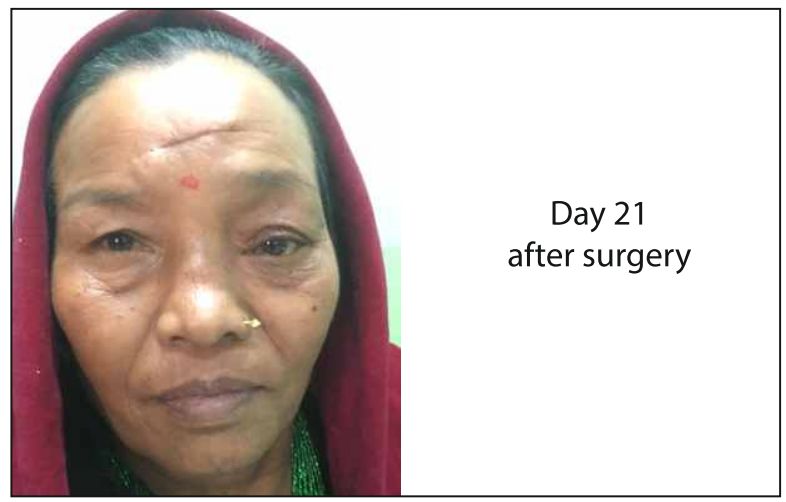

\section{Discussion}

Air-filled spaces around the nasal cavity are called paranasal sinuses which includes the frontal, sphenoid, maxillary and ethmoid sinuses. Sinus ostia are openings of sinus cavities that establishes drainage of paranasal sinuses to nasal cavity. Mucoceles which are benign pseudocyst 
lesion but capable of expansion can arise in any of the paranasal sinuses but since frontal Sinus has defective anatomy to combat or recuperate from any pathological condition it is most commonly affected. It is deeply placed in bone tissue, has thin lining membrane and has relatively poorer nourishment.. Frontal sinus drainage pathway (FSDP) is most complex and variable pathway among paranasal sinuses. Frontal sinus along with FDSP forms Erlenmeyer flask like structure, where neck is frontal ostium. The base of flask i.e. FDSP will then have small opening for drainage. As the nasal floor of frontal sinus is formed by ethmoid bone, infection or pathology can spread to from one to another.-

Aetiology of frontoethmoidal mucocele has not yet been fully elucidated.

But it has been understood due to blockage of frontal ostium owing to chronic processes such as sinusitis, allergies, tumour, idiopathic or previous sinus surgery. The obstruction followed by infection leading to monocyte and lymphocyte stimulation. Thus, there is cytokine production such as IL-1 and IL-6, which promotes resorption and remodelling of bones thus contributing to expansile nature of it. Also other bone resorption promoting factors such as prostaglandin E2 and collagenase is present in the lesion.

The clinical presentation of frontoethmoidal mucocele varies according to size of mucocele and areas involved. The expansive mucocele compressing globe and causing proptosis (95\%) and diplopia is most commonly presenting feature. The compression might also lead to epiphora, eye pain, limitation in eye ball movement $(55 \%)$ and in severe case exposure keratitis and central retinal block. Sometimes, the lesion might erode bone thus simulation neoplasm. Erosion of anterior wall of frontal sinus would lead to wobbly mass beneath periosteum. Erosion of inherent thin posterior wall is more life threatening due to complications such as meningitis, abscess, empyema, pneumoencephaloceles etc. Other presenting signs would be facial pain, nasal obstruction, discharge of mucosa from nasal, facial oedema etc. Also, there might be history of previous sinus surgery such as ethmoidectomy.

Our patient however gave no history of nasal obstruction, sinus surgery, facial pain, headache etc. Our patient presented with two swelling which is a rare incidence.

Differential diagnosis of mucoceles includessalivary adenoma, encephaloceles, meningioma, cholesterol granuloma, epidermoid cyst, chordoma, neurofibroma, paraganglioma, naso-angiofibroma, and malignant neoplasms.If proptosis is associated with mucocele then differentials such as dysthyroid eye disease, retrobulbar orbital tumour, inflammatory pseudo tumour, sinus tumour and metastatic lesion is to be considered. But generally, if there exist insidious onset of proptosis which is painless should make one suspect of mucocele of paranasal sinuses more so if accompanied by diplopia, facial deep seated pain, epiphora etc.

The diagnosis of mucocele is made based on clinical presentation and radiological findings. CT scan in both axial and coronal plane is preferred radiological investigation because it shows bone involvement, intracranial extension, to delineate extend of lesion and also will be helpful in guiding surgical approach. But if neoplasm is suspected and disease is uncertain then MRI can also be ordered. In our patient, no intracranial lesion was seen, but the expansile nature of lesion was noted

The treatment of choice in frontoethmoidal mucocele like other paranasal mucocele is surgical. The type of surgery depends upon available resources and extension of lesion. Surgeon may undergo minimally invasive endoscopic sinus surgeryor external approach of opening obliteration such as craniotomy, frontoethmoidectomy (Lynch's procedure) or osteoplastic sinusotomy of Macbeth, osteoplastic procedure of Goodale-and-Montgomery. If there is lateral extension of frontal mucocele, endoscopic approach might be difficult so combined approached is preferred. Naso-sinusal endoscopic surgery with marsupialization preserving the epithelium is referred surgical 
technique. It is minimally invasive and preserves sinus architecture. Wider the marsupialization of mucocele better is the outcome because of minimization of scar tissue formation and lesser chance of recurrence. With endoscopic approach Hartley et al reported no complication in series of small paediatric population. In case series of 10 patients with paranasal sinuses reported by Namavar et al, endoscopic trans nasal technique to access mucoceles with intra-orbital extension was successful with no recurrence or postoperative complications in follow-up clinic.

\section{Conclusion}

Frontoethmoidal mucocele is the most common mucocele of paranasal sinuses due to its rather convoluted anatomy. The most common presentation is proptosis and diplopia due to lesion pushing eye globe. Endoscopic marsupialisation is preferred surgical technique because it is minimally invasive, has low morbidity, aesthetically no scar is present and also has much fewer complications and recurrence.

\section{Bibliography}

1. Capra GG, Carbone PN, Mullin DP. Paranasal Sinus Mucocele. Head Neck Pathol. 2012 May 24;6(3):369-72.

2. Ch'ng SW, Pillai MB, Morton C. Frontal sinus mucoceles presenting in the upper eyelid: an easily missed diagnosis. BMJ Case Rep [Internet]. 2012 Jun 5 [cited 2019 Apr 18];2012. Available from:https://www.ncbi.nlm.nih.gov/pmc

\section{/articles/PMC4543026/}

3. Neupane Y, Pradhan B, Khanal S. An unsual Presentation of Fronto-ethmoidal Mucocele. Nepal J ENT Head Neck Surg. 2010 Jun;1(1).

4. Pradhan B. Endoscopic Marsupialization of Fronto Ethmoidal Mucocele. Nepal J ENT Head NeckSurg. 2012;3(2):29-30.

5. Palmer J, Schipor I. 9 Frontal-Orbital-Ethmoid Mucoceles.:7.
6. Peral Cagigal B, Barrientos Lezcano J, Floriano Blanco R, García Cantera JM, Sánchez Cuéllar LA, Verrier Hernández A. Mucocele del seno frontal con extensión intraorbitaria e intracraneal. Med Oral Patol Oral Cir Bucal Internet. 2006 Dec;11(6):527-30.

7. Jesberg S. SURGICAL TREATMENT OF CHRONIC FRONTAL SINUSITIS. Arch Otolaryngol. $1946 \operatorname{Jan} 1 ; 43(1): 66-9$.

8. Daniels $\mathrm{DL}$, Mafee MF, Smith MM, Smith $T L$, Naidich TP, Brown WD, et al. The Frontal Sinus Drainage Pathway and Related Structures. Am J Neuroradiol. 2003 Sep 1;24(8):1618-27.

9. Vicente $A$ de $O$, Chaves AG, Takahashi EN, Akaki F, Sampaio AA, Matsuyama C. Frontoethmoidal mucoceles: a case report and literature review. Rev Bras Otorrinolaringol. 2004 Dec;70(6):850-4.

10. Kochhar L, Chaudhry S, Kumar A. FRONTOETHMOIDAL MUCOCELE: A Case Report. Med J Armed Forces India. 1995 Oct;51 (4):290.

11. Namavar. Paranasal sinus mucocele (endoscopic marsupialization and surgical outcome) [Internet]. [cited 2019 Apr 19]. Available from: http://www.ejo.eg.net/article.asp? is $n=1012-5574$; year $=2012$; volume $=28$ ;issue $=2 ;$ spage $=95$;epage $=97$; aulast $=$ Namavar

\section{Corresponding author:}

Dr. Bibhu Pradhan,

Ganesh Man Singh Memorial Academy of ENT and Head and Neck Studies, TU Teaching Hospital, Kathmandu, Nepal 